\title{
The influence of single-nucleotide polymorphisms on overall survival and toxicity in cabazitaxel-treated patients with metastatic castration-resistant prostate cancer
}

\author{
Bodine P. S. Belderbos ${ }^{1} \cdot$ Mirjam de With $^{1,2} \cdot$ Rajbir K. Singh $^{1} \cdot$ Bram C. Agema $^{2} \cdot$ Samira El Bouazzaoui ${ }^{2}$. \\ Esther Oomen-de Hoop ${ }^{1} \cdot$ Ronald de Wit $^{1} \cdot$ Ron H. N. van Schaik ${ }^{2} \cdot$ Ron H. J. Mathijssen ${ }^{1} \cdot$ Sander Bins $^{1}$ (D)
}

Received: 29 July 2019 / Accepted: 7 December 2019

(c) Springer-Verlag GmbH Germany, part of Springer Nature 2020

\begin{abstract}
Purpose Cabazitaxel, used in patients with metastatic castration-resistant prostate cancer (mCRPC), is associated with adverse events which may require dose reductions or discontinuation of treatment. We investigated the potential association of single-nucleotide polymorphisms (SNPs) in genes encoding drug transporters and drug-metabolizing enzymes with cabazitaxel toxicity, overall survival (OS) and pharmacokinetics (PK).

Methods A total of 128 cabazitaxel-treated mCRPC patients, of whom prospectively collected data on toxicity and OS were available and $24 \mathrm{mCRPC}$ patients with available cabazitaxel PK measurements, were genotyped using genomic DNA obtained from EDTA blood. The SLCO1B1 (388A > G; *1B; rs2306283 and $521 \mathrm{~T}>\mathrm{C}$; *5; rs4149056 and haplotype SLCO1B1*15), SLCO1B3 (334 T> G; rs4149117), CYP3A4 (*22; rs35599367), CYP3A5 (*3; rs776746), ABCB1 (3435C > T; rs 1045642), and $T U B B 1(57+87 \mathrm{~A}>\mathrm{C}$; rs463312) SNPs were tested for their association with clinical and PK parameters by univariate/ multivariate logistic regression, log-rank test, or Kruskal-Wallis test.

Results The $S L C O 1 B 1 * 15$ haplotype was significantly associated with a lower incidence of leukopenia and neutropenia ( $p=0.020$ and $p=0.028$, respectively). Patients harboring a homozygous variant for $S L C O 1 B 1 * 1 B$ experienced higher rate $\geq$ grade $3(p=0.042)$. None of the SNPs were associated with pharmacokinetics or OS.

Conclusions In this study, SLCO1B1 $(S L C O 1 B 1 * 15$ and $S L C O 1 B 1 * 1 B)$ was associated with cabazitaxel-induced adverse events in mCRPC patients. As the associations were opposite to previous studies in other drugs and contradicted an underlying pharmacokinetic rationale, these findings are likely to be false-positive and would ideally be validated with even larger (pharmacokinetic) cohorts.
\end{abstract}

Keywords Pharmacogenetic pathway analysis $\cdot$ SNPs $\cdot$ mCRPC $\cdot$ Toxicity $\cdot$ Survival $\cdot$ Pharmacokinetics cabazitaxel

Bodine P. S. Belderbos and Mirjam de With have contributed equally to this work.

Electronic supplementary material The online version of this article (https://doi.org/10.1007/s00280-019-04011-0) contains supplementary material, which is available to authorized users.

Sander Bins

s.bins@erasmusmc.nl

1 Department of Medical Oncology, Erasmus MC Cancer Institute, Dr. Molewaterplein 40, 3015 GD Rotterdam, The Netherlands

2 Department of Clinical Chemistry, Erasmus University Medical Center, Rotterdam, The Netherlands

\section{Introduction}

Cabazitaxel has been approved as chemotherapy for patients with metastatic castration-resistant prostate cancer (mCRPC) after progression on docetaxel [1]. Still, its administration is often hampered by substantial toxicity, resulting in dose reductions (12\%), treatment delays (28\%), and discontinuation of treatment (18\%) [1]. Most common severe adverse events include neutropenia (50-80\%), febrile neutropenia (8\%), leukopenia (40-70\%), fatigue (4-5\%), and diarrhea (4-6\%) [1-3]. Occurrence of $\geq$ grade 3 neutropenia has been associated with higher exposure of cabazitaxel, as well as with a survival benefit in mCRPC patients [4, 5]. This may indicate that there is a delicate balance between toxic, effective, and sub-therapeutic cabazitaxel exposure. Like most 
chemotherapeutic agents, cabazitaxel is dosed on body surface area (BSA), although this still results in an inter-patient variability in clearance of $24 \%$ [6]. This inter-patient variability might be explained by patient-related, disease-related, and environmental factors [7]. Patient-related factors might contain different activity of proteins involved in metabolism or transport of cabazitaxel, which can be caused by germline genetic variations.

Taxanes are substrate of the transmembrane transporters $\mathrm{P}$-glycoprotein (P-gp, encoded by the gene $A B C B 1$ ), OATP1B1 (SLCO1B1) and OATP1B3 (SLCO1B3) and are mainly metabolized by isoenzymes CYP3A4 and CYP3A5 (80-90\%) and to a lesser extent by CYP2C8 in the liver [8-11]. Single nucleotide polymorphisms (SNPs) in the genes encoding for these transporters and enzymes can alter protein activity and consequently result in an increased inter-patient variability in cabazitaxel exposure. In previous research investigating these SNPs, female CYP3A4*22 carriers were found to be at increased risk of grade 3-4 toxicity during docetaxel treatment and of neurotoxicity during paclitaxel treatment $[12,13]$. In patients with advanced urothelial cell carcinoma (UCC) treated with cabazitaxel, $C Y P 3 A 5^{*} 1$ has been associated with a reduced risk of gastrointestinal toxicity and a shorter progression-free survival (PFS) [14]. Additionally, genetic polymorphisms in CYP3A4 and $C Y P 3 A 5$ have been associated with an increased docetaxel clearance [15]. $A B C B 1$ polymorphisms were found to be related to increased grade 3-4 toxicity [14]. SNPs in $S L C O 1 B 1$ and SLCO1B3 were not shown to be associated in pharmacokinetic differences in docetaxel in European population [16, 17]. In Asian nasopharyngeal cancer patients, however, carriers of a homozygous variant (GG) at SLCO1B3 had lower docetaxel clearance and therefore, higher docetaxel concentrations [18]. Polymorphisms in $S L C O 1 B$ have not been associated with clinical outcomes during taxane therapy, but downregulation of the influx pump OATP1B3 is associated with in vitro taxane resistance [11] and may therefore affect survival. Another gene that may play a role in taxane resistance, and possibly survival, encodes for $\beta$-tubulin isoform, the binding site of taxanes on microtubules. A missense polymorphism in that gene (TUBB1) has been identified as significantly associated with reduced survival in cabazitaxel-treated UCC patients $[10,14]$.

In the current study, we therefore assessed the association of SNPs in SLCO1B1 (rs2306283 and rs4149056), SLCO1B3 (rs4149117), CYP3A4 (rs35599367), CYP3A5 (rs776746), ABCB1 (rs1045642), and TUBB1 (rs463312) with survival and toxicity in mCRPC patients treated with cabazitaxel. Additionally, we assessed the association of these genetic variations to cabazitaxel pharmacokinetics (PK) in the mCRPC setting. Ultimately, better understanding of mechanisms underlying inter-patient variability can potentially be applied to individualize treatment in these patients.

\section{Material and methods}

\section{Study design and participants}

In this exploratory post hoc analysis, docetaxel pre-treated mCRPC patients who had received cabazitaxel therapy and were included in one of the three different clinical trials performed in the Netherlands between December 2011 and June 2016 were analyzed. The three trials were the CABARESC trial [2], a pharmacokinetic prequel study of that trial (EudraCT number 2011-003346-40) [2], and the CABENZA trial [19].

The original CABARESC trial aimed to examine the effects of budesonide on cabazitaxel-induced diarrhea in docetaxel pre-treated mCRPC patients. Clinical data on toxicity and survival were prospectively collected for these patients. Before conducting the CABARESC trial, a prequel study in $18 \mathrm{mCRPC}$ patients was performed to ensure that budesonide did not affect cabazitaxel PK [2]. Demographics and clinical outcomes of the patients included in the PK prequel study were obtained retrospectively from their medical records. In the CABENZA trial, the difference in cabazitaxel PK with or without concomitant enzalutamide was investigated in mCRPC patients eligible for cabazitaxel therapy. Since these patients were temporarily treated with the combination therapy, their clinical outcome data were not collected. The data of the CABARESC trial and its PK prequel study were used to investigate the influence of SNPs on clinical outcome (i.e. survival and toxicity), whereas the data of the monotherapy cycles in the CABENZA study and of the CABARESC PK prequel study were used to identify the effect of SNPs on PK of cabazitaxel. Details of the trial designs are summarized in the Supplementary Methods. All patients had given written informed consent and the prospective trials were performed according to the latest version of the Declaration of Helsinki.

\section{Survival, toxicity, and PK}

Overall survival (OS) was defined as the period between the date of study registration to either the date of death from any cause or the date at which patients were last known to be alive at the end of the study. Toxicity was graded when it increased from baseline, according to the Common Terminology Criteria for Adverse Events (CTCAE) v4.3. The non-hematological adverse events included in this analysis were vomiting, nausea, diarrhea, sensory peripheral neuropathy, fatigue, anorexia, alopecia, allergic reaction, and fever. In addition, hematological adverse events like anemia, 
leukopenia, thrombocytopenia, neutropenia, and febrile neutropenia were included. Blood samples $(4 \mathrm{~mL}$, lithium heparin tube) were withdrawn at 12 different timepoints over $24 \mathrm{~h}$ and analyzed by validated liquid chromatography with tandem mass spectrometry methods (UP-MS/MS). PK parameters included in the analysis were $\mathrm{AUC}_{0-24 \mathrm{~h}}, C_{\max }$ and $t_{1 / 2}$.

\section{SNP selection}

Seven potentially relevant SNPs in six genes involved in the metabolism or working mechanism of cabazitaxel were identified (Table 1). These polymorphisms were selected based on previous research reporting potential associations with toxicity and survival.

\section{DNA isolation and genotyping}

DNA isolation was performed in whole-blood samples collected in EDTA tubes, of which $400 \mu \mathrm{L}$ was extracted on the Mag-NAPure Compact instrument (Roche Diagnostics GmbH, Mannheim, Germany) using the Nucleic Acid Isolation kit I (Roche Diagnostics GmbH, Mannheim, Germany), eventually resulting in $20 \mathrm{ng}$ genomic DNA. This genomic DNA was mixed with allele-specific fluorescent-labeled primers and probes and a TaqMan GTXpress Master Mix (Applied Biosystems, Life Technologies Europe BV, Bleijswijk, The Netherlands) to conduct qPCR. qPCR consisted of 40 cycles of denaturation at $95{ }^{\circ} \mathrm{C}$ during $20 \mathrm{~s}$, followed by annealing transpired at $92{ }^{\circ} \mathrm{C}$ for $3 \mathrm{~s}$ and the extension phase at a temperature of $60{ }^{\circ} \mathrm{C}$ for $30 \mathrm{~s}$. Genotypes were scored by measuring allele-specific fluorescence using the Taqman 7500 software (Applied Biosystems, Life Technologies Europe BV, Bleijswijk, The Netherlands) for allelic discrimination.

\section{Statistical analyses}

The distribution of the different studied SNPs in the study population was tested according to the Hardy-Weinberg equilibrium using Chi-squared test. Polymorphisms with a minor allele frequency of $<1 \%$ were not analyzed. SNPs on the same gene were tested for linkage disequilibrium (LD) by calculating $R^{2}$ using LDlink (https://ldlink.nci.nih.gov/). The limit for LD was set at $R^{2}>0.8$. In Utah Residents originated from North and West Europe (CEU population), the SLCO1B1 studied SNPs were in partial LD, consequently resulting in an additional haplotype (SLCO1B1*15) [20]. The selected SNPs or haplotypes were fitted in the most appropriate model. Dominant and recessive models were tested against toxicity endpoints using the Fisher's exact test or the Chi-squared test, depending on the size of the groups. Additionally, an additive model was tested for which logistic regression analysis was used to investigate the association between the studied SNPs included as categorical variables and toxicity. Toxicity endpoints were dichotomized at two cut-offs: toxicity $\geq$ grade 1 and toxicity $\geq$ grade 3 . Overall survival (OS) was analyzed using Cox regression analysis. Univariable genetic associations with $p<0.1$ were entered in multivariable analysis as dependent variable if an end point occurred in at least ten patients per genotype. Baseline

Table 1 Studied SNPs

Survival/toxicity analy- PK analysis, $n=24$

sis, $n=128$

\begin{tabular}{|c|c|c|c|c|c|c|}
\hline Gene & rs number & Common allele name & Position (p12 assembly) & MAF & $\begin{array}{l}\text { Genotypes, } n(\%) \\
\text { WT; HT; HOMO }\end{array}$ & $\begin{array}{l}\text { Genotypes, } n(\%) \\
\text { WT; HT; HOMO }\end{array}$ \\
\hline SLCO1B1 & $\begin{array}{l}\mathrm{rs} 2306283388 \mathrm{~A}>\mathrm{G} \\
\mathrm{rs} 4149056521 \mathrm{~T}>\mathrm{C}\end{array}$ & $\begin{array}{l}S L C O 1 B 1 * 1 B \\
S L C O 1 B 1 * 5 \\
S L C O 1 B 1 * 15\end{array}$ & $\begin{array}{l}21,176,804 \\
21,178,615\end{array}$ & $\begin{array}{l}44 \% \\
14 \%\end{array}$ & $\begin{array}{l}46(36 \%) ; 54(42 \%) ; 28 \\
(22 \%) \\
93(73 \%) ; 33(26 \%) ; \\
2(1 \%) \\
\text { WT } 98(77 \%) ; \operatorname{Var} 30 \\
\quad(23 \%)\end{array}$ & $\begin{array}{l}9(38 \%) ; 11(46 \%) ; 4 \\
\quad(16 \%) \\
18(75 \%) ; 6(25 \%) ; 0(\%) \\
\text { WT 19 (79\%); Var } 5 \\
\quad(21 \%)\end{array}$ \\
\hline$S L C O 1 B 3$ & rs4149117 $334 \mathrm{~T}>\mathrm{G}$ & NA & $20,858,546$ & $88 \%$ & $\begin{array}{l}1(1 \%) ; 29(22 \%) ; 98 \\
\quad(77 \%)\end{array}$ & $0(0 \%) ; 2(8 \%) ; 22(92 \%)$ \\
\hline CYP $3 A 4$ & rs35599367 G >A & $C Y P 3 A 4 * 22$ & $99,768,693$ & $7 \%$ & $\begin{array}{l}110(86 \%) ; 17(13 \%) \\
1(1 \%)\end{array}$ & $\begin{array}{l}19(79 \%) ; 5(21 \%) ; 0 \\
\quad(0 \%)\end{array}$ \\
\hline CYP3A5 & rs776746 G > A & $C Y P 3 A 5 * 3$ & $99,672,916$ & $7 \%$ & $\begin{array}{l}108(84 \%) ; 19(15 \%) ; \\
1(1 \%)\end{array}$ & $\begin{array}{l}19(79 \%) ; 4(17 \%) ; 0 \\
\quad(0 \%) ; \text { Missing } 1(4 \%)\end{array}$ \\
\hline$A B C B 1$ & rs1045642 3435C $>\mathrm{T}$ & NA & $87,509,329$ & $55 \%$ & $\begin{array}{l}29(23 \%) ; 57(44 \%) ; 42 \\
\quad(33 \%)\end{array}$ & $\begin{array}{l}6(25 \%) ; 10(42 \%) ; 8 \\
\quad(33 \%)\end{array}$ \\
\hline$T U B B 1$ & rs463312 $57+87 \mathrm{~A}>\mathrm{C}$ & NA & $59,022,915$ & $7 \%$ & $\begin{array}{l}111(87 \%) ; 17(13 \%) \\
0(0 \%)\end{array}$ & $\begin{array}{l}21(88 \%) ; 3(12 \%), 0 \\
\quad(0 \%)\end{array}$ \\
\hline
\end{tabular}

$M A F$ minor allele frequency, $W T$ wildtype, $H T$ heterozygous, $H O M O$ homozygous, Var variant $S L C O 1 B 1 * 15, N A$ not applicable 
factors (WHO performance status, age or hematological laboratory results) with $p<0.1$ were added in multivariable analysis as independent variables. Multivariable analysis was performed using logistic or Cox regression analysis. As for the PK analysis, the influence of SNPs on cabazitaxel exposure was tested by the Mann-Whitney $U$ test or Kruskal-Wallis test, based on the number of groups. Both univariable and multivariable toxicity associations with $p<0.1$ were internally validated by bootstrapping. For this purpose, one thousand bootstrap samples were generated and the bias-corrected 95\% CIs were calculated for ORs. All statistical analyses were performed using SPSS version 21 . A two-sided $p<0.05$ was considered significant.

\section{Results}

\section{Patients and treatment}

From a total of 281 patients included in all three trials combined [2, 19], 128 patients could be analyzed for the association of polymorphisms with toxicity and survival and 24 patients could be analyzed for the association with cabazitaxel PK (Supplementary Fig. 1). All these patients started 3-week cabazitaxel treatment at $25 \mathrm{mg} / \mathrm{m}^{2}$ and received a median of seven cycles (IQR 4-9). Baseline characteristics of these patients are depicted in Table 2 .

\section{Toxicity, overall survival, and pharmacokinetics}

The most relevant associations of the investigated SNPs with toxicity are displayed in Table 3 . A total overview of all associations with a $p$ value $<0.1$ in the univariable
Table 2 Baseline characteristics total patient cohort

\begin{tabular}{lll}
\hline Characteristics & $\begin{array}{l}\text { Survival/toxicity analysis } \\
(n=128)\end{array}$ & PK analysis $(n=24)$ \\
\hline Age (median, IQR) & $68(63-73)$ & $67(63-73)$ \\
WHO PS & $56(44 \%)$ & $3(12.5 \%)$ \\
0 & $72(56 \%)$ & $21(87.5 \%)$ \\
$1-2$ & & \\
Nr. previous chemotherapies & $114(89 \%)$ & $16(67 \%)$ \\
1 & $14(11 \%)$ & $8(33 \%)$ \\
$\geq 2$ & $6.1(2.8-11.2)$ & $6.4(3.4-10.0)$ \\
Months since last therapy (median, IQR) & & $232(75-382)$ \\
Lab results (median, IQR) & $173(55-354)$ & $7.7(6.5-8.2)$ \\
PSA ( $\mu$ g/L) & $7.7(6.7-8.2)$ & $42(39-43)$ \\
Hb (mmol/L) & $3936-43)$ & $138(82-337)$ \\
Albumin $(\mathrm{g} / \mathrm{L})$ & $142(96-291)$ & $224(190-316)$ \\
AP $(\mathrm{U} / \mathrm{L})$ & $322(216-480)$ & \\
LDH (U/L) &
\end{tabular}

$I Q R$ interquartile range, WHO PS World Health Organization performance status, PSA prostate-specific antigen, $H b$ hemoglobin, $A P$ alkaline phosphatase, $L D H$ lactate dehydrogenase

Table 3 Significant associations of SNPs with toxicity

\begin{tabular}{|c|c|c|c|c|c|c|}
\hline \multirow[t]{2}{*}{ Endpoint } & \multirow[t]{2}{*}{ Factor } & \multirow[t]{2}{*}{ Genotype } & \multicolumn{2}{|l|}{ Univariable } & \multicolumn{2}{|l|}{ Multivariable } \\
\hline & & & OR $(95 \%$ CI $)$ & $p$ & OR $(95 \%$ CI $)$ & $p$ \\
\hline Toxicity $\geq$ grade 3 & $\begin{array}{l}\text { WHO PS }(1-2 \text { vs } 0) \\
S L C O 1 B 1 * 1 B(388 \mathrm{~A}>\mathrm{G}) \\
S L C O 1 B 3(334 \mathrm{~T}>\mathrm{G})\end{array}$ & $\begin{array}{l}\text { GG vs } \mathrm{AA}+\mathrm{AG} \\
\mathrm{GG} \text { vs } \mathrm{TT}+\mathrm{TG}\end{array}$ & $\begin{array}{l}2.495(1.205-5.165) \\
2.318(0.983-5.464) \\
0.367(0.157-0.855)\end{array}$ & $\begin{array}{l}0.014 \\
0.051 \\
0.018\end{array}$ & $\begin{array}{l}2.448(1.136-5.274) \\
2.569(1.034-6.383) \\
0.441(0.182-1.068)\end{array}$ & $\begin{array}{l}0.022 \\
0.042 \\
0.070\end{array}$ \\
\hline Leukopenia & $S L C O 1 B 1 * 15$ & *15 vs No*15 & $0.371(0.158-0.869)$ & 0.020 & & \\
\hline Neutropenia & $\begin{array}{l}\text { WHO PS (1-2 vs } 0) \\
S L C O 1 B 1 * 15\end{array}$ & $* 15$ vs No*15 & $\begin{array}{l}0.524(0.243-1.129) \\
0.380(0.164-0.882)\end{array}$ & $\begin{array}{l}0.099 \\
0.022\end{array}$ & $\begin{array}{l}0.530(0.242-1.160) \\
0.384(0.164-0.900)\end{array}$ & $\begin{array}{l}0.112 \\
0.028\end{array}$ \\
\hline
\end{tabular}

OR odds ratio, WHO PS World Health Organization performance status 
analyses is given in Supplementary Table 1. The haplotype $S L C O 1 B 1 * 15(388 \mathrm{~A}>\mathrm{G}$ and $521 \mathrm{~T}>\mathrm{C})$ was associated with all grade neutropenia, even after correction for WHO performance status (OR 0.38, 95\% CI 0.16-0.90, $p=0.028$ ), and with all grade leukopenia (OR $0.37,95 \%$ CI $0.16-0.90, p=0.020)$. The presence of a homozygous variant in $S L C O 1 B 1^{*} 1 B$ was associated with an increased risk of toxicity $\geq$ grade 3 , corrected for WHO performance score and SLCO1B3 $334 \mathrm{~T}>\mathrm{G}$. Bootstrapping resulted in similar CIs in these analyses (Supplementary Table 1).

The TUBBI 128A > C variant was associated with a reduced OS in univariable analysis, but this association did not hold after correction for baseline factors (Supplementary Table 2). The remaining SNPs were not associated with OS. Moreover, none of the SNPs were associated with one of the pharmacokinetic parameters of cabazitaxel (Supplementary Table 3).

\section{Discussion}

In this exploratory pharmacogenetic analysis in men with mCRPC treated with cabazitaxel, several new associations between genetic polymorphisms and cabazitaxel-related toxicities were found. The haplotype $(* 15)$ of SLCO1B1 SNPs $(388 \mathrm{~A}>\mathrm{G}$ and $521 \mathrm{~T}>\mathrm{C})$ resulted in a reduced incidence of leukopenia and neutropenia; the latter even after correction for WHO performance status (Table 3). As neutropenia is the most frequent adverse reaction of cabazitaxel treatment $(80 \%)$ and the most common reason for cabazitaxel discontinuation [21], identification of predictors for neutropenia is important for clinical practice. In addition, it was found that one mutant allele of $S L C O 1 B 1388 \mathrm{~A}>\mathrm{G}$ resulted in an increased incidence of grade 3 (or higher grade of) toxicity. The isolated hepatic expression of both OATP1B1 and OATP1B3 [22] leaves little room for alternative hypotheses than an influence of these SNPs on toxicity via increased systemic cabazitaxel exposure. However, this PK-based rationale is contradicted by the fact that none of the investigated SLCO SNPs or haplotypes were significantly associated with systemic exposure. Moreover, in previous pharmacogenetic association studies, these $S L C O$ SNPs were not associated with docetaxel PK [16, 17, 23]. Ultimately, the observed associations are opposite to the expected working mechanism of the genetically varied proteins. Previously published literature showed that one variant G-allele at codon 388 of $S L C O 1 B 1$ (rs2306283) increases the activity of the hepatic influx transporter OATP1B1, while one variant $C$ allele at codon 521 (rs4149056) leads to a reduced OATP1B1 activity [24] and the haplotype $S L C O 1 B 1 * 15$ also leads to reduced OATP1B1 function [20]. Therefore, the expected increase and decrease in toxicity are opposite to the observed direction of the association between the $S L C O$
SNPs and toxicity. The previously reported associations of the SLCO1B1 SNPs with statin, sorafenib, irinotecan, and methotrexate toxicity show that these polymorphisms are truly associated with toxicity [25-28], which is in line with the working mechanism of the altered protein function, and thus in contrast with the results from this study. This contrast can possibly be explained by a substrate-specific effect of the studied SNPs, as was previously found for $A B C B 11199 \mathrm{G}>$ A SNP [29]. The effect of taxanes on the working mechanisms of the studied SLCOIBI SNPs is an interesting research topic and never been performed before. For other taxanes, like paclitaxel and docetaxel, the role of $S L C O$ polymorphisms on developing adverse events has not been specified either [15].

Although the studied SNPs in TUBBI and SLCO1B3 have been associated with survival and taxane therapy previously $[14,30]$, none of the SNPs remained significantly associated with OS in our cohort. A variant allele at TUBB1 $57+87 \mathrm{~A}>\mathrm{C}$ was associated univariably with OS, but correction for baseline clinical parameters disproved this finding.

Despite the found associations were internally validated, the main limitation of this study is its explorative character, which is refraining us from determining a causal relation of the found associations. Similarly, the contradictory findings in the $S L C O$ polymorphisms might be attributed to coincidence by multiple testing. Although this is the largest genetic association study in cabazitaxel-treated patients so far, the relatively low minor allele frequencies at some of the SNPs and the small number of patients in the PK analyses might have influenced our results, which would ideally be validated in even larger prospective cohorts, in which other possible explanations for altered cabazitaxel pharmacokinetics, e.g. drug-drug interactions, can also be taken into account.

\section{Conclusions}

In this study with prospectively collected data, an association between genetic variations in SLCO (haplotype $S L C O 1 B 1 * 15$ and $S L C O 1 B 1 * 1 B)$ and relevant cabazitaxelinduced toxicity in mCRPC patients was found. However, these associations could not be explained by PK differences and, moreover, the observed effect of the SLCO1B1 SNPs was opposite to the expected altered working mechanism of the OATP1B1 protein. Therefore, larger prospective pharmacokinetic studies are needed to investigate the role of variations in $S L C O$ on systemic cabazitaxel exposure and eventually cabazitaxel-induced toxicity.

Funding None. 


\section{Compliance with ethical standards}

Conflict of interest Bodine Belderbos has received travel support from Astellas. Ronald de Wit has received advisory fees from Sanofi, Merck, Lilly, Roche, Bayer, Janssen, and Clovis. He has received speaker fees from Sanofi and Merck and research funding (Institutional) from Sanofi and Bayer. Ron Mathijssen has received research funding (Institutional) from Sanofi and Astellas. The other authors declare that they have no conflict of interest.

Informed consent Informed consent was obtained from all individual participants included in this article.

\section{References}

1. de Bono JS, Oudard S, Ozguroglu M, Hansen S, Machiels JP, Kocak I, Gravis G, Bodrogi I, Mackenzie MJ, Shen L, Roessner M, Gupta S, Sartor AO, Investigators T (2010) Prednisone plus cabazitaxel or mitoxantrone for metastatic castration-resistant prostate cancer progressing after docetaxel treatment: a randomised open-label trial. Lancet 376(9747):1147-1154

2. Nieuweboer AJ, de Graan AM, Hamberg P, Bins S, van Soest RJ, van Alphen RJ, Bergman AM, Beeker A, van Halteren H, Ten Tije AJ, Zuetenhorst H, van der Meer N, Chitu D, de Wit R, Mathijssen RH, Dutch Uro-Oncology S (2017) Effects of budesonide on cabazitaxel pharmacokinetics and cabazitaxel-induced diarrhea: a randomized, open-label multicenter phase II study. Clin Cancer Res 23(7):1679-1683

3. Eisenberger M, Hardy-Bessard AC, Kim CS, Geczi L, Ford D, Mourey L, Carles J, Parente P, Font A, Kacso G, Chadjaa M, Zhang W, Bernard J, de Bono J (2017) Phase III study comparing a reduced dose of cabazitaxel $(20 \mathrm{mg} / \mathrm{m} 2)$ and the currently approved dose $(25 \mathrm{mg} / \mathrm{m} 2)$ in postdocetaxel patients with metastatic castration-resistant prostate cancer-PROSELICA. J Clin Oncol 35(28):3198-3206

4. NDA (2013) https://www.accessdata.fda.gov/drugsatfda_docs/ nda/2010/201023s000ClinPharmR.pdf.

5. Meisel A, von Felten S, Vogt DR, Liewen H, de Wit R, de Bono J, Sartor O, Stenner-Liewen F (2016) Severe neutropenia during cabazitaxel treatment is associated with survival benefit in men with metastatic castration-resistant prostate cancer (mCRPC): a post-hoc analysis of the TROPIC phase III trial. Eur J Cancer 56:93-100

6. Janssen A, Verkleij CPM, van der Vlist A, Mathijssen RHJ, Bloemendal HJ, Ter Heine R (2017) Towards better dose individualisation: metabolic phenotyping to predict cabazitaxel pharmacokinetics in men with prostate cancer. Br J Cancer 116(10):1312-1317

7. Ferron GM, Dai Y, Semiond D (2013) Population pharmacokinetics of cabazitaxel in patients with advanced solid tumors. Cancer Chemother Pharmacol 71(3):681-692

8. Pean E, Demolis P, Moreau A, Hemmings RJ, O'Connor D, Brown D, Shepard T, Abadie E, Pignatti F (2012) The European medicines agency review of cabazitaxel $(\operatorname{Jevtana}(\mathrm{R}))$ for the treatment of hormone-refractory metastatic prostate cancer: summary of the scientific assessment of the committee for medicinal products for human use. Oncologist 17(4):543-549

9. Nieuweboer AJ, Hu S, Gui C, Hagenbuch B, Ghobadi Moghaddam-Helmantel IM, Gibson AA, de Bruijn P, Mathijssen RH, Sparreboom A (2014) Influence of drug formulation on OATP1B-mediated transport of paclitaxel. Cancer Res 74(11):3137-3145

10. Marsh S (2006) Taxane pharmacogenetics. Per Med 3(1):33-43
11. de Morree ES, Bottcher R, van Soest RJ, Aghai A, de Ridder CM, Gibson AA, Mathijssen RH, Burger H, Wiemer EA, Sparreboom A, de Wit R, van Weerden WM (2016) Loss of SLCO1B3 drives taxane resistance in prostate cancer. Br J Cancer 115(6):674-681

12. Sim S, Bergh J, Hellstrom M, Hatschek T, Xie H (2018) Pharmacogenetic impact of docetaxel on neoadjuvant treatment of breast cancer patients. Pharmacogenomics 19(16):1259-1268

13. de Graan AJ, Elens L, Sprowl JA, Sparreboom A, Friberg LE, van der Holt B, de Raaf PJ, de Bruijn P, Engels FK, Eskens FA, Wiemer EA, Verweij J, Mathijssen RH, van Schaik RH (2013) CYP3A4*22 genotype and systemic exposure affect paclitaxelinduced neurotoxicity. Clin Cancer Res 19(12):3316-3324

14. Duran I, Hagen C, Arranz JA, Apellaniz-Ruiz M, Perez-Valderrama B, Sala N, Lainez N, Garcia-Del Muro X, Nogueron E, Climent MA, Maroto P, Font A, Garcia-Donas J, Gallardo E, LopezCriado P, Gonzalez Del Alba A, Saez MI, Vazquez S, Luque R, Rodriguez-Antona C (2016) SNPs associated with activity and toxicity of cabazitaxel in patients with advanced urothelial cell carcinoma. Pharmacogenomics 17(5):463-471

15. Nieuweboer AJ, de Morree ES, de Graan AJ, Sparreboom A, de Wit R, Mathijssen RH (2015) Inter-patient variability in docetaxel pharmacokinetics: a review. Cancer Treat Rev 41(7):605-613

16. de Graan AJ, Lancaster CS, Obaidat A, Hagenbuch B, Elens L, Friberg LE, de Bruijn P, Hu S, Gibson AA, Bruun GH, Corydon TJ, Mikkelsen TS, Walker AL, Du G, Loos WJ, van Schaik RH, Baker SD, Mathijssen RH, Sparreboom A (2012) Influence of polymorphic OATP1B-type carriers on the disposition of docetaxel. Clin Cancer Res 18(16):4433-4440

17. Lewis LD, Miller AA, Owzar K, Bies RR, Markova S, Jiang C, Kroetz DL, Egorin MJ, McLeod HL, Ratain MJ, Alliance for Clinical Trials in O (2013) The relationship of polymorphisms in $\mathrm{ABCC} 2$ and SLCO1B3 with docetaxel pharmacokinetics and neutropenia: CALGB 60805 (Alliance). Pharmacogenet Genom 23(1):29-33

18. Chew SC, Singh O, Chen X, Ramasamy RD, Kulkarni T, Lee EJ, Tan EH, Lim WT, Chowbay B (2011) The effects of CYP3A4, CYP3A5, ABCB1, ABCC2, ABCG2 and SLCO1B3 single nucleotide polymorphisms on the pharmacokinetics and pharmacodynamics of docetaxel in nasopharyngeal carcinoma patients. Cancer Chemother Pharmacol 67(6):1471-1478

19. Belderbos BPS, Bins S, van Leeuwen RWF, Oomen-de Hoop E, van der Meer N, de Bruijn P, Hamberg P, Overkleeft ENM, van der Deure WM, Lolkema MP, de Wit R, Mathijssen RHJ (2018) Influence of enzalutamide on cabazitaxel pharmacokinetics: a drug-drug interaction study in metastatic castration-resistant prostate cancer (mCRPC) patients. Clin Cancer Res 24(3):541-546

20. Oshiro C, Mangravite L, Klein T, Altman R (2010) PharmGKB very important pharmacogene: SLCO1B1. Pharmacogenet Genomics 20(3):211-216. https://doi.org/10.1097/FPC.0b013 e328333b99c

21. Genzyme S (2017) SmPC Jevtana. https://www.medicines.org.uk/ emc/product/4541/smpc. Accessed 18 Apr 2019

22. Uhlen M, Fagerberg L, Hallstrom BM, Lindskog C, Oksvold P, Mardinoglu A, Sivertsson A, Kampf C, Sjostedt E, Asplund A, Olsson I, Edlund K, Lundberg E, Navani S, Szigyarto CA, Odeberg J, Djureinovic D, Takanen JO, Hober S, Alm T, Edqvist PH, Berling H, Tegel H, Mulder J, Rockberg J, Nilsson P, Schwenk JM, Hamsten M, von Feilitzen K, Forsberg M, Persson L, Johansson F, Zwahlen M, von Heijne G, Nielsen J, Ponten F (2015) Proteomics. Tissue-based map of the human proteome. Science 347(6220):1260419

23. Baker SD, Verweij J, Cusatis GA, van Schaik RH, Marsh S, Orwick SJ, Franke RM, Hu S, Schuetz EG, Lamba V, Messersmith WA, Wolff AC, Carducci MA, Sparreboom A (2009) Pharmacogenetic pathway analysis of docetaxel elimination. Clin Pharmacol Ther 85(2): $155-163$ 
24. Ieiri I, Higuchi S, Sugiyama Y (2009) Genetic polymorphisms of uptake (OATP1B1, 1B3) and efflux (MRP2, BCRP) transporters: implications for inter-individual differences in the pharmacokinetics and pharmacodynamics of statins and other clinically relevant drugs. Exp Opin Drug Metab Toxicol 5(7):703-729

25. Bins S, Lenting A, El Bouazzaoui S, van Doorn L, Oomen-de Hoop E, Eskens FA, van Schaik RH, Mathijssen RH (2016) Polymorphisms in SLCO1B1 and UGT1A1 are associated with sorafenib-induced toxicity. Pharmacogenomics 17(14):1483-1490

26. Xiang Q, Zhang X, Ma L, Hu K, Zhang Z, Mu G, Xie Q, Chen S, Cui Y (2018) The association between the SLCO1B1, apolipoprotein E, and CYP2C9 genes and lipid response to fluvastatin: a meta-analysis. Pharmacogenet Genomics 28(12):261-267

27. Yang L, Wu H, Gelder TV, Matic M, Ruan JS, Han Y, Xie RX (2017) SLCO1B1 rs4149056 genetic polymorphism predicting methotrexate toxicity in Chinese patients with non-Hodgkin lymphoma. Pharmacogenomics 18(17):1557-1562

28. Zair ZM, Singer DR (2016) Influx transporter variants as predictors of cancer chemotherapy-induced toxicity: systematic review and meta-analysis. Pharmacogenomics 17(10):1189-1205
29. Dessilly G, Elens L, Panin N, Karmani L, Demoulin JB, Haufroid V (1199G) ABCB1 1199G\%3eA polymorphism (rs2229109) affects the transport of imatinib, nilotinib and dasatinib. Pharmacogenomics 17(8):883-890

30. Wright JL, Kwon EM, Ostrander EA, Montgomery RB, Lin DW, Vessella R, Stanford JL, Mostaghel EA (2011) Expression of SLCO transport genes in castration-resistant prostate cancer and impact of genetic variation in SLCO1B3 and SLCO2B1 on prostate cancer outcomes. Cancer Epidemiol Biomarkers Prev 20(4):619-627

Publisher's Note Springer Nature remains neutral with regard to jurisdictional claims in published maps and institutional affiliations. 